\title{
NotAS SOBRE O ESTADO ADMINISTRATIVO: DE OMISSIVO A HiPERATIVO
}

EGON BOCKMANN MOREIRA ${ }^{\dagger}$

\section{UM DOSSIÊ SOBRE ESTADO ADMINISTRATIVO}

RESUMO: Originalmente concebido para ser omissivo, o Estado Administrativo cresceu e se multiplicou. $O$ artigo examina a ideia original e os seus desdobramentos, dentro da noção de que, hoje, existem muitos Estados dentro do mesmo Estado. Logo, é preciso que nos apercebamos disso e desenvolvamos metodologias distintas para cada espécie de Estado Administrativo.

Palavras-Chave: Estado Administrativo; Estado de Bem-Estar; Estado Empresário; Estado Regulador; Estado-Ambiental.

ABSTRACT: Originally conceived to be omissive, the Administrative State grew and multiplied. The article analyses the original idea and its implications, given the notion that today there are many States within the same State. Therefore, we need to develop different methodologies for each type of State Administration.

KEYWORDS: Administrative State; Welfare State; Entrepreneurial State; Regulatory State; Environmental State.

\footnotetext{
${ }^{\dagger}$ Mestre e Doutor em Direito do Estado pela Universidade Federal do Paraná (UFPR). Professor Associado da Faculdade de Direito e do Programa de Pós-Graduação em Direito da UFPR. Professor Visitante na Faculdade de Direito da Universidade de Lisboa (2011). E-mail: egon@xvbm.com.br.
} 


\section{SUMÁRIO:}

I. INTRODUÇÃO..................................................................................................155

II. O ALVORECER DO ESTADO ADMINISTRATIVO ...............................156

III. A PRIMEIRA GRANDE MUTAÇÃO: O ESTADO-DE-BEM-ESTAR.........159

IV. A SEGUNDA GRANDE MUTAÇÃO: O ESTADO-EMPRESÁRIO................162

V. A TERCEIRA GRANDE MUTAÇÃO: O ESTADO-REGULADOR E O ESTADO-DE-GARANTIA ...........................................................166

VI. A QUARTA GRANDE MUTAÇÃO: O ESTADO-AMBIENTAL ...................172

VII. CONSIDERAÇÕES FINAIS: O ESTADO ADMINISTRATIVO QUE NÃO SE CANSA DE SURPREENDER..............................................174

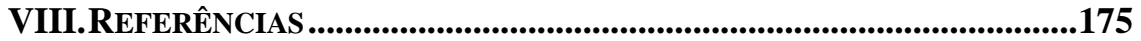

\section{TABLE OF CONTENTS:}

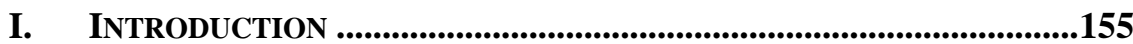

II. THE DAWN OF THE ADMINISTRATIVE STATE .....................................156

III. THE FIRST BIG MUTATION: THE WELLFARE STATE .........................159

IV. THE SECOND BIG MUTATION: THE BUSINESS STATE .......................162

V. THE THIRD BIG MUTATION: THE REgUlatory STATE AND THE GUARANTOR STATE............................................................166

VI. THE FOURTH BIG MUTATION: THE ENVIRONMENTAL STATE .........172

VII. FINAL CONSIDERARIONS: THE ADMINISTRATIVE STATE THAT IS NOT TIRED OF SURPRISING ........................................174

VIII.REFERENCES ..............................................................................................175 


\section{INTRODUÇÃO}

Se tomarmos como referência a Revolução Francesa, seguida das decisões do Conselho de Estado do século XIX, podemos afirmar que a ideia de Estado Administrativo foi criada com o intuito de restringir e vigiar os poderes públicos. O Direito Administrativo brasileiro foi orientado por tais premissas, ${ }^{1}$ que permaneceram únicas até o primeiro terço do século XX. Pretendia-se que o Estado não interagisse com as pessoas privadas, mas se limitasse às tarefas definidas como públicas, na sua esfera de atribuições normativas. Caso violasse tais premissas, seria controlado objetiva e negativamente: a respectiva jurisdição se encarregava de inibir a conduta administrativa abusiva ou ilegal.

Ocorre que, também no caso brasileiro, houve momentos em que a legislação passou a atribuir tarefas outras ao Estado-Administração (sobretudo pós-Constituição de 1934). Ao invés de estatuir só a omissão, igualmente lhe imputou múltiplas ações em variados setores socioeconômicos. O Estado deixou de apenas praticar a gestão dos negócios endoadministrativos (e suas repercussões em face das pessoas privadas), mas passou a agir intensamente em vários setores de repercussão social (bem-estar social, empresas estatais, etc.). Mais: o Estado Administrativo passou a ser constituído dessa forma.

Essa narrativa veio crescendo até o início deste século XXI, quando a expansão passou a constituir formas bastante mais complexas de atuação estatal. Antes singelo e até monotemático, o Estado Administrativo assumiu também as vestes de um Estado-de-Garantia - isso sem se falar do Estado-Ambiental. Todas essas facetas vinculadas à mesma Administração Pública, desdobrando-se simultaneamente em vários planos de ação. Ou seja, são muitos os Estados-Administração dentro de um só Estado.

De igual modo e especialmente em outros países, o Estado Administrativo deixou de ser somente nacional, pois passou a assumir foros transnacionais e internacionais. Não será demais dizer que, por um lado, a Administração Pública transborda suas fronteiras (como nos impactos do Direito Ambiental e nas demandas de saúde pública) e, por outro, a Administração Pública internacional ingressa em setores internos (como no caso da União Europeia).

O que temos é o Estado Administrativo multifacetado, tanto em

${ }^{1}$ Cf. ALMEIDA, Fernando Dias Menezes de. Formação da Teoria do Direito

Administrativo no Brasil. São Paulo, SP: Quartier Latin, 2015; e GUANDALINI JÚNIOR, Walter. História do Direito Administrativo Brasileiro: Formação (18211895). Curitiba, PR: Juruá, 2016. 
termos materiais quanto formais e/ou geográficos. A concepção originária dos séculos XVIII e XIX não mais vive sozinha, mas se vê constrangida a adotar diferentes personalidades. $\mathrm{O}$ seu habitat natural gerou e/ou foi invadido por outras espécies de Estado Administrativo, algumas agressivas o suficiente para submeter e subverter a sua primeira configuração.

Daí o escopo deste breve ensaio, que apenas pretende lançar algumas poucas luzes sobre tais muitos Estados dentro - e fora - de um só Estado, bem como a respeito das múltiplas Administrações Públicas que nele(s) se organizam. A intenção é a mais simples de todas: chamar a atenção para a complexidade daquilo que poderia ser chamado de EstadoAdministração contemporâneo a este século XXI.

\section{O ALVORECER DO ESTADO ADMINISTRATIVO}

Conforme mencionado, com as revoluções burguesas seguidas das decisões da jurisdição administrativa francesa, nasceu a disciplina relativa à atribuição e exercício das competências do Estado (i.e., o Direito Administrativo). Já não mais se poderia cogitar de poderes imediatamente oriundos da pessoa do soberano (subjetivos), mas de competências originárias da lei (objetivas). Esse paradigma se tornou a principal marca dos poderes atribuídos ao Estado, configurando-o como Estado Administrativo: aquele cuja ação deve ser de acordo com o Direito Administrativo, o direito da Administração Pública.

Essa peculiaridade fez do Direito Administrativo uma disciplina pretensamente universal (ao menos nos países de raiz romano-germânica do ocidente), pois concebida como controle institucionalizado, formal e material, da atividade dos poderes públicos. Trata-se de seu eixo central, em torno do qual foram criados e gravitam os demais conceitos. Não só se preocupa com o funcionamento dos órgãos, entidades e agentes públicos, mas, sobretudo, com a garantia das pessoas privadas quanto ao respeito de seus direitos, visando a impedir o arbítrio da Administração. A sua finalidade é a de tornar oficial e positivamente arraigado o controle jurídico-institucional do poder administrativo do Estado, de modo objetivo: quando muito, as pessoas privadas poderiam colaborar com o controle da legalidade (eis que não detinham direitos subjetivos frente ao Estado Administrativo ${ }^{2}$ ).

2 Ampliar em: MARQUES NETO, Floriano de Azevedo, A Bipolaridade do Direito Administrativo e sua Superação. In: Carlos Ari Sundfeld; Guilherme Jardim Jurksaitis 
Isso implicou a concepção de que o Estado, que administra a moeda, cobra impostos e exerce o monopólio da violência, deve ter as suas competências minuciosamente disciplinadas em normas jurídicas. Assim, o Direito Administrativo visou a tornar jurídico-administrativa toda a atividade do Estado: simplesmente não há Administração Pública aquém ou além do Direito (e da lei). Eventuais desvios ingressam naquilo que Gomes Canotilho denomina de "Estado de não direito": "aquele que identifica o direito com a 'razão do Estado', com o 'bem do povo', com a 'utilidade política', autoritária ou totalitariamente imposto." ${ }^{3} \mathrm{O}$ poder administrativo do Estado tornou-se nada mais do que o dever definido pela lei: a competência para a prática de atos administrativos, em outras palavras.

Se bem atentarmos, as definições do Direito Administrativo, lavradas por célebres juristas em diferentes épocas e diversos sistemas, confirmam a assertiva. A preocupação essencial diz respeito à contenção do poder público e respectiva submissão objetiva ao princípio da legalidade. Alguns poucos exemplos merecem ser conferidos, para ilustrar o debate.

Comecemos por alguns dos clássicos europeus. Assim, a definição do publicista italiano V. E. Orlando contempla o Direito Administrativo como "o sistema daqueles princípios jurídicos que regulam a atividade do Estado para o atingimento de seus fins." É o poder que age, dirigido à consecução de escopo juridicamente preestabelecido. ${ }^{4}$ Outro exemplo é o austríaco Adolf Merkl, que define o Direito Administrativo como "um produto da Constituição e das fontes jurídicas subordinadas a ela, e regra

(Orgs.). Contratos Públicos e Direito Administrativo. São Paulo, SP: Malheiros Editores/SBDP/FGV, 2015, pp. 354-415; e MOREIRA, Egon Bockmann. O Princípio da Legalidade, a Lei e o Direito. In: Thiago Marrara (Org.). Princípios de Direito Administrativo: Legalidade, Segurança Jurídica, Impessoalidade, Publicidade, Motivação, Eficiência, Moralidade, Razoabilidade, Interesse Público. São Paulo, SP: Atlas, 2012, pp. 45-61.

${ }^{3}$ GOMES CANOTILHO, José Joaquim. Estado de Direito. Lisboa: Gradiva, 1999, p. 12. Aliás, não será demais afirmar que essa concepção envolve a própria essência do constitucionalismo: "a primeira função de uma ordem político-constitucional foi e continua sendo realizada através de um sistema de limites impostos àqueles que exercem o poder político." GOMES CANOTILHO, José Joaquim. Direito Constitucional e Teoria da Constituição. 5ae ed. Coimbra: Almedina, 2002, p. 71. Idêntica é a compreensão de COMPARATO, Fábio Konder. Legitimidade do Poder de Reforma Constitucional. In: Fábio Konder Comparato. Direito Público: Estudos e Pareceres. São Paulo, SP: Saraiva, 1996, p. 25 e ss.

${ }^{4}$ ORLANDO, Vittorio Emanuele. Principii di Diritto Amministrativo. $4^{a}$ ed. Firenze: G. Barbèra, 1910, p. 20 (tradução livre). 
produtora da administração." 5

Já o acurado doutrinador francês Prosper Weil consigna o seguinte:

O direito administrativo não procura somente assegurar à actividade administrativa a expansão que lhe permita realizar os seus fins de interesse geral. Tende também a proteger o indivíduo das ameaças de um poder sempre perigoso para os direitos e liberdades individuais. Historicamente, aí reside mesmo a primeira e principal inspiração de nossa disciplina (...) foi graças a ela que o francês é um cidadão e não um súbdito. ${ }^{6}$

No Brasil, Oswaldo Aranha Bandeira de Mello definiu o Direito Administrativo como "o ordenamento jurídico da atividade EstadoPoder, enquanto tal, ou das pessoas de direito que façam as suas vezes, de criação e realização de utilidade pública, levada a efeito de maneira direta e imediata." 7

Note-se que essa ideia central é também descrita por Caio Tácito, nos seguintes termos:

A juridicidade da administração pública é fruto do liberalismo político. Os direitos do homem geram os deveres do Estado. Nos regimes absolutos, o administrador - veículo da vontade do soberano - é, como este, irresponsável. A administração é, apenas, uma técnica a serviço de privilégios de nascimento. O estado de direito, ao contrário, submete o Poder ao domínio da lei: a atividade arbitrária se transforma em atividade jurídica. ${ }^{8}$

A referência a esse rol heterogêneo de autores presta-se apenas a demonstrar os pontos comuns na abordagem. O essencial é a concepção da juridicidade como requisito limitador da ação pública. Não há incertezas quanto à constatação de que a face dinâmica do poder estatal é definida pelo Direito Administrativo: aqui, é precisamente delimitado o Estado Administrativo.

Por conseguinte, o Estado-Administração, considerado sob a perspectiva do Direito Constitucional e do Administrativo, nasceu com a

${ }^{5}$ MERKL, Adolf. Teoría General del Derecho Administrativo. Madri: Editorial Revista de Derecho Privado, 1935, p. 114.

${ }^{6}$ WEIL, Prosper. O Direito Administrativo. Trad. Maria da Gloria Ferreira Pinto. Coimbra: Almedina, 1977, p. 105.

${ }_{7}$ BANDEIRA DE MELLO, Oswaldo Aranha. Princípios Gerais de Direito

Administrativo, Vol. I. $2^{\underline{a}}$ ed. Rio de Janeiro, RJ: Forense, 1979, p. 36.

8 TÁCITO, Caio. Direito Administrativo. São Paulo, SP: Saraiva, 1975, p. 1. 
finalidade de exorbitar do Direito dito Comum e assim disciplinar a organização administrativa (órgãos, entidades e agentes públicos); a ação administrativa (atos e contratos); os bens públicos (assim qualificados por sua destinação); o poder de polícia (limitações ao exercício das liberdades privadas) e a responsabilidade patrimonial pública. Não havia direitos subjetivos públicos da pessoa privada em face da Administração, nem relações jurídico-administrativas, mas apenas a aplicação objetiva da lei e seu controle, com as mesmas características. No princípio, era o limite e o limite estava na lei.

Porém, não se olvide que o poder, mesmo aquele oriundo de normas jurídicas (configurando dever positivado), traz consigo inegável tentação para ultrapassar suas fronteiras. Quanto maior o poder, mais acentuada sua tendência à ruptura. A criatividade humana é um constante desafio à legalidade. O que igualmente deu margem ao incessante alargamento do Direito Administrativo e, em consequência, do que se pode entender por Estado-Administração.

\section{A PRIMEIRA GRANDE MUTAÇÃO: O ESTADO DE BEM-ESTAR}

Antes de ingressarmos na primeira ordem de mutações do Estado Administrativo, uma ressalva merece ser feita. Como o leitor constatará, o exame das transformações corresponde, num paralelismo assimétrico, à ideia das dimensões (ou gerações ou camadas) de direitos fundamentais. ${ }^{9}$ A Administração Pública modificou-se também em razão dos direitos das pessoas privadas frente ao Estado: deixou de se omitir e passou a agir positivamente em favor do bem-estar social. A ideia de direito subjetivo público é consolidada, bem como as relações jurídicoadministrativas - que deixam de ser meramente objetivas (subsunção da lei). Modificações paulatinas, que foram se acrescentando historicamente. Apesar de não haver referências únicas, nem substituições, o que se pode tentar é a estratificação analítica, com o intuito de auxiliar a compreensão do Estado-de-Bem-Estar.

Com efeito, se pudéssemos falar propriamente de instantes de geração do Estado-de-Bem-Estar nos sistemas capitalistas ocidentais, eles poderiam ser a repercussão da Primeira Guerra Mundial na Europa (pós1919); da Grande Depressão, nos EUA (pós-1929); e da Constituição de

9 Tema que merece ser aprofundado no dossiê "Taxonomia das Gerações de Direitos", constante da Revista de Estudos Institucionais, Vol. 2, 2 (2016). Disponível em:

$<$ https://www.estudosinstitucionais.com/REI/issue/view/3/showToc $>$. Acesso em: 15 de junho de 2017. 
1934, no Brasil. Em todos os casos, o seu marco zero advém da constatação de que o bem-estar social não se origina apenas de garantias às liberdades clássicas conjugadas com a omissão do Estado Administrativo, mas que é preciso haver condutas públicas que instalem condições mínimas de dignidade à pessoa e inibam o abuso do poder econômico. $\mathrm{O}$ Estado houve de se tornar ativo em relação a certos eventos e se valeu do Direito para tornar essa ação factível. Tais normas impuseram ao Estado-Administração a transposição de suas barreiras endógenas, com a finalidade de atuar positivamente e desenvolver benefícios coletivos (muitos de usufruto individual, mas com efeitos sociais positivos).

A partir de então, a economia deixou de ser assunto reservado às pessoas privadas e se tornou uma questão de Estado - tão importante quanto a separação de poderes, a garantia de direitos e a proteção à soberania (afinal, foi alçada às Constituições). Igualmente, constatou-se que, quando deixadas ao livre arbítrio das pessoas privadas, as falhas de mercado e respectivos abusos de poder econômico tendem a se intensificar (monopólios, oligopólios, trustes, cartéis, sindicatos, etc.). Em contrapartida, o Direito Administrativo parou de pensar apenas nas restrições objetivas ao Estado Administrativo e houve de se dedicar à ampliação de suas competências: os direitos subjetivos das pessoas privadas instalavam relações jurídico-administrativas, as quais demandavam ações positivas por parte do Estado-de-Bem-Estar. ${ }^{10}$

Tanto isso é verdade que as Constituições passaram a se dedicar, com intensidade crescente, a assuntos econômicos. São normas fundamentais - e mesmo capítulos inteiros - que se referem à presença proativa do Estado na economia e ao relacionamento econômico entre as pessoas privadas. A partida foi dada pelas Constituições do México, de 1917, e da Alemanha, de 1919 (a célebre Constituição de Weimar), que alteraram o fundamental do relacionamento jurídico entre o Estado e a economia. No caso brasileiro, a Constituição de 1934 deu esse primeiro passo (apesar de

${ }^{10}$ O que importou não só a consolidação dos direitos fundamentais de segunda dimensão em seu caráter material, mas também o nascimento de processos administrativos - relações jurídico-administrativas processuais - de segunda dimensão, nos quais o devido processo legal não se prestar a inibir a ação do Estado, mas sim a provoca-la. Situação que implicará correspondentes processos de outras dimensões no que respeita às próximas mutações do Estado Administrativo. Cf. MOREIRA, Egon Bockmann. Processo Administrativo: Princípios Constitucionais, a Lei 9.784/1999 e o Código de Processo Civil/2015. 5ª ed. São Paulo, SP: Malheiros Editores, 2017, pp. 74-79. 
a Revolução de 1930 e respectiva legislação autoritária terem desempenhado papel relevante $\left.{ }^{11}\right)$.

Já pautado pelas normas constitucionais, o Estado se reapropriou da economia: não só no sentido de prestar benefícios às pessoas privadas, mas também por meio de decisões-chave e da titularidade de bens e fatores de produção (e sua administração), passando pela fixação de normas jurídicas disciplinadoras do comportamento dos agentes econômicos. Foi a positivação de normas jurídicas - sobretudo nas Constituições - que consolidou o papel reservado ao Direito nas relações econômicas, transmudando o Estado-Administração para Estado-deBem-Estar-Social. De omissivo, o Estado foi transformado em prestador.

Logo, as relações econômicas travadas pelo Poder Público foram elevadas ao grau mais importante da normatividade: passaram a integrar a Constituição, tornando-se parte do fundamento objetivo de todas as demais normas do sistema, estabelecendo deveres públicos quanto a determinados assuntos e declarando direitos fundamentais de cunho econômico. Por isso, não será demais dizer que as Leis Fundamentais constituíram Estados que até então não existiam, os quais continham, mas muitas vezes nem sequer se pareciam com o Estado Administrativo original.

Bem vistas as coisas, antes era a Administração Pública dos órgãos, do poder de polícia, dos bens e de alguns serviços. Aos Poderes Públicos estava constitucionalmente vedado se envolverem na economia, vez que dela haviam sido expulsos pelas revoluções setecentistas. Ocorre que este Estado-Administração - tipicamente Guarda-Noturno, pois zelava pela segurança sem perturbar o descanso das pessoas privadas - foi constitucionalmente transformado no Welfare State, no Estado-de-BemEstar Social, que imediatamente prestava serviços às pessoas privadas.

Esta alteração formal veio acompanhada na severa modificação do papel substancial reservado ao Estado: não mais lhe cabia manter o status quo (garantindo a ordem e segurança pública: poder de polícia), mas sim constituir novas situações até então inexistentes (benefícios sociais coletivos: serviços públicos). O Estado-de-Bem-Estar Social é sobretudo um Estado prospectivo, que visa a modificar o status quo, por meio da tutela ativa de direitos sociais. Porém, as transformações não foram apenas estas.

Depois dessa viragem histórica, o Estado passou a conviver com a Administração interventiva e promocional, ampliando paulatinamente

${ }^{11}$ Cf. MOREIRA, Egon Bockmann. Anotações sobre a História do Direito Econômico Brasileiro (Parte I: 1930-1956). Revista de Direito Público da Economia - RDPE, Vol. 2, 6, 2004.

3 JOURNAL OF INSTITUTIONAL STUDIES 1 (2017) 
seu espectro de ação. Para além da reserva quanto à polícia administrativa, o Poder Público viu-se obrigado a produzir bens e serviços e disciplinar a economia - além de estabelecer regras e sistemas de controle referentes a abusos. Isso até descobrir o maravilhoso mundo do poder econômico das empresas estatais.

\section{A SEGUNDA GRANDE MUTAÇÃO: O ESTADO-EMPRESÁRIO}

Tal como em tantos outros aspectos das transformações do Estado Administrativo, também no caso das estatais o caso brasileiro é peculiar. O tema foi inicialmente positivado na legislação infraconstitucional, acompanhando as políticas públicas definidas ad hoc pelos governantes: aos poucos, com variações de intensidade, foram criadas autarquias econômicas (a Caixa Econômica Federal, criada em 1861, é exemplo marcante), empresas públicas e sociedades de economia mista. As subsidiárias e respectiva multiplicação de espectro dá-se durante a década de 1970 - a impulsionar o denominado "milagre econômico", combinado com inflação, endividamento externo e incremento das contas públicas. $^{12}$

Também aqui, o assunto assumiu tamanha importância que passou a ser incorporado ao texto constitucional. Isso se deu depois do primeiro momento de relacionamento constitucional do Estado-Administração brasileiro com a economia: de início, o bem-estar; em seguida, as sociedades empresariais. $\mathrm{O}$ esboço de tais previsões começa na Constituição de 1946, em parcos dispositivos relativos às empresas estatais (limitados às proibições da celebração de negócios e acumulação de cargos por parte de servidores públicos: arts. 48, 181 e 185). O constituinte ainda não se preocupara com a criação, funcionamento e limites das sociedades empresariais públicas.

Apesar disso, é justamente a partir dessa época que se consolida o Estado-Empresário como técnica por meio da qual o Poder Público veio a se tornar um dos principais agentes econômicos brasileiros (senão o principal), muitas vezes em situações monopolísticas (rectius: privilégios criados pelo legislador). Nesse cenário, em 1952 foi fundado o Banco Nacional de Desenvolvimento Econômico - BNDE (Lei no 1.628), com o escopo de acelerar o processo de diversificação industrial por meio do

${ }^{12}$ A esse respeito e por todos, cf. NUNES, António José Avelãs. Industrialização e Desenvolvimento: a economia política do "modelo brasileiro de desenvolvimento". São Paulo, SP: Quartier Latin, 2005. 
reaparelhamento e fomento. Em 1953, criou-se a Petróleo Brasileiro S. A. - Petrobras (Lei o 2.004), calcada também na campanha pública contra a espoliação dos "trustes internacionais". Tais exemplos demonstram que o Estado transmudou-se e passou a fomentar e a participar de empresas privadas, bem como constituir as suas próprias: já não era mais o gestor de órgãos, bens e serviços públicos, mas sim agente econômico de especial envergadura.

Pois foi na Constituição de 1967 que o tema assumiu a estatura que hoje conhecemos. O art. 163, em seguida à positivação expressa do princípio da subsidiariedade, consigna preceito significativo em seu $\S 2$, que, pela primeira vez, traz ao nível constitucional as expressões empresa pública e sociedade de economia mista:

Na exploração, pelo Estado, da atividade econômica, as empresas públicas, as autarquias e sociedades de economia mista reger-se-ão pelas normas aplicáveis às empresas privadas, inclusive quanto ao direito do trabalho e das obrigações.

Em seguida, o $\S 3^{0}$ exclui privilégios tributários de empresa pública "que explorar atividade não monopolizada", submetendo-as ao mesmo regime aplicável às empresas privadas.

Veja-se bem a relevância que o tema assumiu na configuração do Estado brasileiro. O Poder Constituinte já não mais se preocupava apenas com a tríade clássica (organização do Estado, regime de governo e direitos fundamentais), unida aos direitos sociais, mas ia além: a "exploração da atividade econômica" por meio de empresas sob controle societário do Estado tornou-se assunto importante demais para ser relegado ao estatuto infraconstitucional. Isso fez com que o legislador ordinário - muitas vezes acionado pelo Executivo (decretos-lei e iniciativa de lei) - se sentisse muito à vontade para multiplicar as instâncias de poder econômico estatal. O Estado Administrativo brasileiro desdobrou-se num grande empresário.

Conforme prenunciado pela matriz constitucional de 1967, as sociedades empresárias públicas aumentaram em número e atividade, transformando-se em elemento decisivo para o modelo econômico brasileiro. Se é fato que o legislador ordinário não se esforçou em prestigiar as liberdades econômicas clássicas (livre iniciativa e livre concorrência foram relegadas às "folhas de papel"), o mesmo não se deu quanto à criação de empresas estatais. Como destacou Alberto Venâncio Filho:

pode-se dizer que a Constituição de 1967 adotou uma linha em que tenta coibir

3 JOURNAL OF INSTITUTIONAL STUDIES 1 (2017) 
a intervenção do Estado, atribuindo à iniciativa privada a maior responsabilidade pela condição das atividades econômicas. Constando tais princípios de normas programáticas, não representaram, entretanto, nenhuma mudança na orientação que até então vinha sendo seguida pelo Estado brasileiro, que cada vez mais aumente a esfera de interferência na atividade econômica, seja através da simples regulamentação, seja através da exploração direta dessas atividades econômicas. ${ }^{13}$

Em outras palavras, o Estado-Administração passou a agir continuamente no cenário econômico (não mais só a intervir, portanto). Outrora excepcionais, as sociedades empresárias sob o poder de controle do Estado tornaram-se dado usual do cotidiano. Desde então, integram a Constituição brasileira e conformam a compreensão que possamos ter do Estado.

Ocorre que, conforme anota Luiz Aranha Corrêa do Lago, o período de 1967-1973 "caracterizou-se como o de maior intensidade de criação de novas empresas públicas no Brasil" [...] "foram criadas, entre 1968 e 1974, 231 novas empresas públicas (sendo 175 na área de serviços, 42 na indústria de transformação, 12 em mineração e 2 na agricultura)" ${ }^{14}$ Caio Tácito traz informação que confirma essa ordem de grandeza: "em estudo feito pela Fundação Getúlio Vargas, em 1970, entre as 20 maiores indústrias brasileiras, 10 eram empresas estatais."15 Com isso, como anotou Werner Baer, as empresas estatais dominavam os setores de:

aço, mineração e produtos petroquímicos e controlavam mais de $80 \%$ da capacidade geradora de energia e a maioria dos serviços públicos. Calcula-se que em 1974, entre as cem maiores empresas (em valor de ativos), $74 \%$ dos ativos combinados pertenciam a empresas estatais, enquanto nas 5.113 maiores empresas, $37 \%$ dos ativos pertenciam a estatais. Da mesma forma, os bancos estatais representavam um papel predominante no sistema financeiro. Dos 50 maiores bancos (em termos de depósitos), os estatais eram responsáveis

13 VENÂNCIO FILHO, Alberto. Intervenção do Estado e Liberdade Econômica no

Direito Constitucional Brasileiro. In: Paulo Bonavides, et. al. As Tendências Atuais do

Direito Público: Estudos em Homenagem ao Professor Afonso Arinos de Melo

Franco. Rio de Janeiro, RJ: Forense, 1976, p. 449.

${ }^{14}$ LAGO, Luiz Aranha Corrêa do. A retomada do crescimento e as distorções do "milagre": 1967-1973. In: Marcelo de Paiva Abreu (Org.). A Ordem do Progresso: Cem Anos de Política Econômica Republicana, 1889-1989. Rio de Janeiro, RJ: Campus, 1990, p. 268.

15 TÁCITO, Caio. Direito Administrativo. São Paulo, SP: Saraiva, 1975, p. 194. 
por cerca de $56 \%$ do total de depósitos em 1974 e por cerca de $65 \%$ dos empréstimos feitos ao setor privado. ${ }^{16}$

A toda evidência, tais empresas não surgiram do nada, nem foram isentas de custos. A ampla maioria delas, desde da edição do Decreto-lei no 200/1967 (Organização da Administração Federal), foi criada pela União e instalada por meio de empréstimos em moeda estrangeira (aumentando o endividamento público por vias transversas). Ao controlar empresas, verbas e obras públicas, o governo federal direcionava os investimentos e a alocação de recursos nacionais.

Com o passar do tempo, o outrora acanhado Estado Administrativo tornou-se um enorme e desajeitado Estado-Empresário, atuando em mineração (Companhia Vale do Rio Doce); aço (Companhia Siderúrgica Nacional - CSN; Companhia Siderúrgica Paulista - COSIPA; Usinas Siderúrgicas de Minas Gerais - USIMINAS; Companhia de Ferro e Aço de Vitória - COFAVI; Siderúrgica Brasileira - SIDERBRÁS); petroquímica (Petróleo Brasileiro S.A. - PETROBRAS; Petrobras Química PETROQUISA); ferrovias (Rede Ferroviária Federal S.A. - RFFSA; Ferrovia Paulista S.A. - FEPASA); transportes marítimos (Cia.de Navegação Lloyd Brasileiro; Cia. de Navegação do S. Francisco; Serviços de Transportes da Bahia de Guanabara; Empresa de Navegação da Amazônia; Cia. Brasileira de Dragagem; Cia. Docas da Guanabara; Cia. Docas do Pará); telecomunicações (Cia. Telefônica Brasileira - CTB; Telecomunicações do Rio de Janeiro - TELERJ; Telecomunicações de São Paulo - TELESP; Empresa Brasileira de Telecomunicações - EMBRATEL; Telecomunicações do Paraná - TELEPAR; Telecomunicações de Minas Gerais - TELEMIG; Cia. Riograndense de Telecomunicações - CRT; Telecomunicações Brasileiras, S.A. - TELEBRAS) e eletricidade (Cia. Brasileira de Energia Elétrica - CBEE; Cia. Hidroelétrica do S. Francisco CHESF; FURNAS Centrais Elétricas; Cia. Paulista de Força e Luz - CPFL; Centrais Elétricas do Sul do Brasil - ELETROSUL; Centrais Elétricas Brasileiras - ELETROBRAS). Apesar de os exemplos não serem exaustivos - nem ao nível federal, nem estadual, nem municipal ou distrital -, demonstram a amplitude da presença do Estado nos mais importantes setores da economia brasileira.

Ocorre que, de meados de 1970 ao início dos anos 1980, houve a transição marcada pelos choques do petróleo, unidos ao crescimento da inflação e da dívida externa - que, como já dito, decorreu também da magnitude dos investimentos públicos em empresas controladas pelo

${ }^{16}$ BAER, Werner. A Economia Brasileira. 2 $2^{\underline{a}}$ ed. Trad. Edite Sciulli. São Paulo, SP: Nobel, 2003, p. 98. 
Estado. A dívida pública foi aumentada e exposta à variação cambial. O clímax deu-se em 1979, através da potencialização recíproca de fatos econômicos: inflação; choques do petróleo; taxas de juros mundiais e fatores climáticos adversos agricultura. Como resultado, essas empresas tornaram-se cada vez mais dependentes do governo e das dívidas para financiar seus projetos de investimento. $\mathrm{O}$ déficit público chegava próximo ao insustentável.

Isso fez com que, a partir de 1985, o fenômeno da intervenção do Estado na Ordem Econômica ganhasse novos foros: os assim denominados choques econômicos (por exemplo, os Planos Cruzado; Bresser; Verão; Collor etc.), que submeteram a economia privada. Instalou-se a ciranda inflacionária, que gerou contínua sucessão de planos econômicos, cuja ampla maioria envolveu congelamento de preços e salários, intervindo fortemente em contratos privados e públicos. Nada tinha de omissivo nem de bem-estar esse Estado-Administrador.

Com a estabilização econômica promovida a partir de 1994 com o Plano Real (Lei no 9.069/1995), foi desnudado o cenário trágico em que se encontrava o Estado-Empresário brasileiro: empresas estatais superendividadas, com baixa capacidade de desenvolvimento e estruturação deficitária. Salvo exceções, o Estado Administrativo brasileiro revelou-se um péssimo empresário - prestando-se a institucionalizar o hábito oitocentista dos favores privados com verbas públicas. Igualmente devido a tais razões, o Estado-Empresário tornouse coadjuvante de outros Estados, dois dos quais serão tratados a seguir: o Estado-Regulador e o Estado-de-Garantia.

\section{A TERCEIRA GRANDE MUTAÇÃO: O ESTAdo REGULADOR E O ESTADO DE GARANTIA}

Como vimos, o Estado-Administração cresceu - tanto em termos qualitativos quanto quantitativos. Se bem analisarmos a história constitucional brasileira, o art. 21 da atual Constituição é representativo dessa hipertrofia das atividades atribuídas à União (além da abertura do art. 173, quanto a empresas estatais, e do art. 174, relativamente à regulação e planejamento econômico ${ }^{17}$ ).

${ }_{17}$ Ampliar em MOREIRA, Egon Bockmann. Qual é o Futuro do Direito da Regulação no Brasil? In: Carlos Ari Sundfeld; André Rosilho (Orgs.). Direito da Regulação e Políticas Públicas. São Paulo, SP: Malheiros Editores/SBDP, 2014, p. 107-139. 
Esse aumento desmedido, em tempos nos quais inexistia zelo fiscal (a Lei de Responsabilidade Fiscal data de 2000) nem controle adequado das estatais (a Lei das Estatais é de 2016), fez com que o Estado Administrativo se tornasse um grande e excêntrico empresário (sem as vicissitudes privadas, como a falência de sociedades mal geridas e a responsabilização de seus gestores). Afinal de contas, nem todos podem contar com um sócio controlador que tem presunção de liquidez, em sociedades empresariais revestidas de privilégios legais (mas cujos diretores eram orientados por diretrizes políticas). É evidente que esse alargamento irresponsável traria, mais dia menos dia, complicações fiscais (a ausência de receita a suportar as empresas e a dificuldade em manter programas mínimos de bem-estar ao mais vulneráveis).

Demais disso, ao antigo Estado-Administração também foram atribuídas competências para a prestação do serviços normativamente denominados de públicos (a integrar a ideia de Estado-de-Bem-Estar à de Estado-Empresário). A ele foi cometida a incumbência de assegurar a adequada prestação desses serviços públicos - majoritariamente de forma direta (responsabilidade de execução), mas também por meio dos concessionários ou permissionários (responsabilidade de garantia da prestação).

Com a crise fiscal pela qual passou o Brasil, a partir da década de 1990 intensificou-se a prestação indireta de serviços públicos, na qual a tarefa estatal é ainda mais árdua: uma coisa é fornecer o serviço na justa medida das possibilidades financeiras (e desideratos políticos); outra, bastante mais complexa, é ver se alguém que detém o título de expert em certa atividade, para quem foi constituída nova situação jurídica com forte caráter mandamental (ornamentada por deveres extraordinários e fronteiras de ganhos), está bem executando o contrato.

O déficit nas contas públicas (além de diretrizes políticas), esvaziou o Estado-Empresário, que se viu na contingência de privatizar empresas e atividades estatais: seja por meio da despublicatio absoluta (privatização material, em que transfere a titularidade dos bens e serviços a pessoas privadas - p. ex., o caso dos bancos e das mineradoras), seja por meio de contratos (privatização formal, em que transfere a execução da atividade, por prazo certo, a particulares com autonomia a de gestão dos bens e serviços delegados - p. ex., as concessões de serviço público).

Ora, a privatização formal traz consigo o dever de fiscalizar as concessões, imputado ao concedente para verificar se o concessionário executa o contrato tal como previsto em lei e nos regulamentos (gerais e setoriais), zelando pela boa prestação daquele serviço normativamente qualificado como público. Esta fiscalização tem dupla perspectiva funcional: frente ao concessionário, para supervisionar o cumprimento 
dos deveres e obrigações contratuais; frente aos usuários, para garantir a adequada prestação do serviço. $O$ que dá origem a várias relações multipolares e direitos subjetivos públicos, ampliando a complexidade das relações jurídico-administrativas.

Por conseguinte, o Estado deixa de empreender e passa a regular e a garantir. Não é mais Estado-Empresário nem Estado-de-Bem-Estar, mas Estado-Regulador e/ou Estado-de-Garantia. Afinal, como consignou Gomes Canotilho, o exercício de serviços públicos por pessoas privadas implica:

tão somente a escolha de uma forma outra de prossecução das tarefas públicas. O Estado permanece 'responsável', mas a tarefa pode ser prosseguida e executada com mais efectividade, eficiência e economicidade se se adoptarem os novos padrões de organização. ${ }^{18}$

Esta responsabilidade tem razão de ser: o serviço permanece público, pois normativamente imputado ao Estado. Será por meio da regulação que o Estado garantirá a prestação adequada do serviço que lhe foi normativamente atribuído.

Mas note-se que não se trata de atitude passiva, que porventura autorizasse a inércia estatal - muito pelo contrário. Engana-se quem reputa que as tarefas do Estado tornam-se simples e menos trabalhosas depois da despublicização. Ou que isso pode atenuar a regulamentação da atividade concedida: freer markets, more rules é o título do livro de Stephen K. Vogel que sintetiza a constatação de que liberalizar tem como consequência a expansão da regulação (em extensão e intensidade). ${ }^{19} \mathrm{No}$

${ }^{18}$ GOMES CANOTILHO, José Joaquim. O Direito Constitucional passa; o Direito Administrativo passa também. Studia Juridica, Vol. 61: Estudos em Homenagem ao Prof. Doutor Rogério Soares (Ad Honorem, 1), 2001, p. 717.

${ }^{19}$ Vogel prova empiricamente que a liberalização implicou o crescimento das atividades públicas. A velha regulação foi substituída e incrementada pela nova e mais intensa reregulação: "in most cases of 'deregulation', governments have combined liberalization with reregulation, the reformulation of old rules and the creation of new ones. Hence, we have wound up with freer markets and more rules. In fact, there is often a logical link: liberalization requires reregulation." VOGEL, Steven. Freer Markets, More Rules: Regulatory Reform in Advanced Industrial Countries. New York, NY: Cornell University Press, 1996, p. 3. A liberalização exigiu a reorganização do controle público e de seu exercício - tanto ao expandir a regulação quanto ao estabelecer complexas estratégias regulatórias em termos nacionais, comunitários e globais. 
mesmo sentido, Maria Manuel Leitão Marques escreveu que:

muitas vezes a privatização de uma actividade conduziu à produção de regulação complexa e densa e à criação de novas autoridades reguladoras públicas, que se encarregaram de organizar os mercados em matéria de preços, qualidade, investimentos, fomento da concorrência e protecção dos utentes. Assim, mesmo que as principais empresas tenham sido privatizadas e o acesso liberalizado, certos mercados como o da energia ou das telecomunicações, não perderam, por ora, a sua natureza de mercados regulados. ${ }^{20}$

Isto é, Estado-Regulador não é sinônimo de Estado Mínimo, mas persiste sendo um grande Estado que se retrai em algumas áreas (execução direta) e, simultaneamente, se expande em outras tantas (regulação e garantia da prestação).

O que se acentua no setor de serviços públicos, nos quais as políticas de privatizações obrigaram "a uma densificação da regulação". ${ }^{21}$ No Brasil, a conjugação da reserva constitucional de serviços públicos com a ampliação dos agentes que o prestam em regime de Direito Privado Administrativo (alguns sujeitos aos efeitos do mercado concorrencial) exige níveis mais intensos e profundos tanto da regulação como da fiscalização e garantia.

Este é o retrato do incremento das tarefas estatais em decorrência das privatizações de serviços públicos e de atividades econômicas outrora de titularidade estatal. O Estado Administrativo os transfere a fim de obter vantagens coletivas, muitas vezes em contratos que contêm obrigações outrora não detidas pelo antigo Estado-Empresário:

Concessões nas quais o Estado assume sobretudo tarefas de garantia e controlo, uma vez que a sua tradicional responsabilidade de execução (Erfüllungsverantwortung) tende a ser substituída por uma responsabilidade de garantia da prestação (Gewährleistungsverantwortung) ou, até, por uma mera responsabilidade de controlo ou fiscalização (Beobachtungsverantwortung). ${ }^{22}$

${ }^{20}$ MARQUES, Maria Manuel Leitão. O Acesso aos Mercados Regulados e o Direito da Concorrência. Revista de Direito Público da Economia - RDPE, Vol. 1, 3, 2003.

${ }^{21}$ MOREIRA, Vital. Auto-Regulação Profissional e Administração Pública. Coimbra: Almedina, 1997, p. 43.

${ }^{22}$ ESTORNINHO, Maria João. Concessão de Serviço Público: que futuro? Direito e Justiça, Vol. Especial (VI Colóquio Luso-Espanhol de Direito Administrativo), 2005, p. 22. Sobre o "dever estadual de garantia" na fase pós-privatização, ampliar em GONÇALVES, Pedro Costa. Entidades Privadas com Poderes Públicos: O Exercício 
As tarefas são mais difíceis de ser realizadas e exigem ainda maior responsabilidade em sua concretização.

Com efeito, se for verdadeiro que o Estado Administrativo abdicou de algumas das atividades prestacionais que o caracterizaram durante quase meio século (conjugadas nas vestes do Estado-de-Bem-Estar e do EstadoEmpresário), isso, contudo, não pode ter como consequência a volta a um passado marcado pela passividade estatal. Como anota Pedro Costa Gonçalves, a despublicização não implica "a 'batida em retirada' do Estado, nem, ao jeito de um renovado 'laissez-faireism', a entrega da economia às 'leis de mercado' ou a 'leis jurídicas' de mera definição, enquadramento e protecção da economia e da concorrência." ${ }^{23} \mathrm{O}$ atual Estado de Garantia:

foi chamado a assumir uma nova posição de garante da realização de dois objectivos ou interesses fundamentais: por um lado, o correcto funcionamento dos sectores $e$ serviços privatizados (...), e, por outro, a realização dos direitos dos cidadãos, designadamente dos direitos a beneficiar, em condições acessíveis, de serviços de interesse geral. ${ }^{24}$

Com efeito, a compreensão do Estado-de-Garantia exsurge com clareza num ambiente de privatização material, no qual o EstadoAdministração se retira e por isso garante a disponibilização e a qualidade de bens e serviços outrora seus, mas agora de titularidade

de Poderes Públicos de Autoridade por Entidades Privadas com Funções

Administrativas. Coimbra: Almedina, 2005, p. 158-170; e GONÇALVES, Pedro Costa.

A Concessão de Serviços Públicos: uma aplicação da técnica concessória. Coimbra:

Almedina, 1999, p. 7-23/176/239 e ss. Cf. também SCHIMIDT-ASSMANN, Eberhard.

La Teoría General del Derecho Administrativo como Sistema: Objetos e

Fundamentos de la Constitución Sistemática. Trad. Mariano Bacigalupo, et. al.

Madrid: Instituto Nacional de Administración Pública/Marcial Pons, 2003, p 179-186; e

GOMES CANOTILHO, José Joaquim. O Estado Garantidor: claros-escuros de um conceito. In: António Avelãs Nunes e Jacinto Nelson de Miranda Coutinho (Coords.). O Direito e o Futuro, o Futuro do Direito. Coimbra: Almedina, 2008, p. 571-576. ${ }^{23}$ GONÇALVES, Pedro Costa. Direito Administrativo da regulação. In: Pedro Costa Gonçalves. Regulação, Electricidade e Telecomunicações: estudos de Direito Administrativo da Regulação. Coimbra: Coimbra Editora, 2003, p. 9-11.

${ }^{24}$ GONÇALVES, Pedro Costa. Direito Administrativo da regulação. In: Pedro Costa Gonçalves. Regulação, Electricidade e Telecomunicações: estudos de Direito Administrativo da Regulação. Coimbra: Coimbra Editora, 2003, p. 9-11. 
privada. Mas se é bem verdade que a Administração de garantia mais se coaduna ao cenário da redução material da atividade administrativa, fato é que a privatização formal (concessões, permissões, PPPs, etc.) também traz consigo forte carga de deveres de fiscalização e garantia. Sobremodo no caso brasileiro, insista-se, que conserva o foro constitucional para os serviços públicos. É por meio da regulação e da fiscalização que a Administração Pública preserva a eficiente prestação do serviço. O que se tem é uma técnica diferenciada para a realização da tarefa que foi primariamente cometida aos Poderes Públicos.

Porém, as incidências do Estado-Regulador e do Estado-de-Garantia não se encerram nas privatizações tradicionais. Se refletirmos bem, um dos principais efeitos da Lei Anticorrupção (Lei no 12.846/2013), ao atribuir deveres positivos de compliance e whistle-blowing às empresas e pessoas privadas, foi o de delegar, ope legis, competências públicas (ou, ao menos, compartilhá-las). O Estado deixou de ter atribuições privativas relativamente ao controle da corrupção e as transferiu materialmente às sociedades empresariais - públicas e privadas -, atribuindo-lhes deveres certos e proativos quanto à fiscalização e denúncia (funcionalizando o contrato societário).

Inclusive, o Estado Administrativo não fiscaliza, mas divulga manuais e critérios de controle da corrupção, a fim de que as pessoas privadas os institucionalizem e se responsabilizem por isso, sob pena de o non facere quod debeatur implicar a responsabilidade objetiva da pessoa jurídica. ${ }^{25}$

Note-se bem essa peculiaridade: o Estado Administrativo passou a Estado-de-Bem-Estar por meio do reconhecimento normativo de direitos subjetivos públicos. Quase 100 anos depois, o princípio da legalidade passa a atribuir deveres subjetivos públicos às pessoas privadas, cujo respeito é regulado pelo Estado, que se incumbe de garantir o seu cumprimento (sob pena de severas sanções de Direito Econômico). Porém, se isso já é peculiar, fato é que a configuração normativa de deveres fundamentais

${ }^{25}$ Tais manuais e sistemas são positivados pelo Estado-Administração e se encontram disponíveis em: $<$ http://www.cgu.gov.br/assuntos/responsabilizacao-de-empresas/leianticorrupcao $>$. Acesso em: 20 de junho de 2017. A respeito das peculiaridades extraordinárias da Lei Anticorrupção brasileira, cf. MOREIRA, Egon Bockmann; BAGATIN, Andreia Cristina. Lei Anticorrupção e quatro de seus principais temas: Responsabilidade Objetiva, Desconsideração Societária, Acordos de Leniência e Regulamentos Administrativos. Revista de Direito Público da Economia - RDPE, Vol. 12, 47, 2014. Sobre a delegação de competências dessa ordem e por todos, cf. a magnífica obra GONÇALVES, Pedro Costa. Entidades Privadas com Poderes Públicos: O Exercício de Poderes Públicos de Autoridade por Entidades Privadas com Funções Administrativas. Coimbra: Almedina, 2005. 
assume especial relevância ao estudarmos o Estado-Ambiental.

\section{A QUARTA GRANDE MUTAÇÃO: O ESTAdo AMBIENTAL}

Simultaneamente aos fenômenos prestacional, empresarial, garantístico e regulador, o Estado Administrativo também se transformou num Estado-Ambiental. Isso porque, a partir do momento em que a temática ecológica se tornou um dos tópicos de maior relevância tanto nacional quanto internacionalmente, o legislador não hesitou em alçá-la ao nível normativo constitucional - positivando deveres fundamentais a todos os habitantes e competências diferenciadas aos Poderes Públicos.

O Estado-Ambiental molda o direito constitucional à ética da responsabilidade, à economia sustentável, à função socioambiental da cidade, ao pluralismo cultural e à primazia do bem-estar social através da premissa da dignidade da pessoa humana e da democracia. ${ }^{26}$ Como Peter Häberle destacou, o Estado Constitucional é responsável pelas futuras gerações e, dada essa tarefa, encontra-se incumbido do dever de desenvolver ações protetivas ao meio ambiente, nada mais sendo do que uma prorrogação congenial do Estado-de-Bem-Estar do século XX. ${ }^{27}$ Pela intervenção estatal e responsabilidade solidária em matéria ambiental, as políticas públicas urbanas, de desenvolvimento e sociais devem se moldar aos princípios e diretrizes ambientais, com a formação de um Estado Ambiental de Direito.

${ }^{26} \mathrm{O}$ Estado de Direito Ambiental recebe diversas denominações, todas se reportando a um mesmo significado. Assim, Jesús Jordano Fraga refere-se ao "Estado Ambiental de Direito", enquanto que José Joaquim Gomes Canotilho o trata como "Estado Constitucional Ecológico". Cf. JORDANO FRAGA, Jesús. El Derecho Ambiental del Siglo XXI. Revista de Direito Ambiental, Vol. 9, 36, 2004; e GOMES CANOTILHO, José Joaquim. Estado Constitucional Ecológico e Democracia Sustentada. In: Heline Sivini Ferreira; José Rubens Morato Leite (Orgs.). Estado de Direito Ambiental: tendências, aspectos constitucionais e diagnósticos. Rio de Janeiro, RJ: Forense Universitária, 2004, p. 3-16. Ingo Sarlet, Paulo Affonso Leme Machado e Tiago Fensterseifer trazem mais de 12 expressões que exteriorizam tais ideias. Cf. SARLET, Ingo Wolfgang; MACHADO, Paulo Affonso Leme; FENSTERSEIFER, Tiago. Constituição e Legislação Ambiental Comentadas. São Paulo, SP: Saraiva, 2015, p. 3536.

${ }^{27}$ HÄBERLE, Peter. El Estado Constitucional. Trad. Héctor Fix-Fierro. Ciudad del México: Universidad Nacional Autónoma de México, 2001. 
Com efeito, de um modelo de interferência pontual, caracterizado por legislações esparsas e difusas e instrumentos de controle, a tutela do meio ambiente recebe um modelo de interferência global. Nesse contexto, uma das mudanças paradigmáticas trazidas pela Constituição diz respeito às formas como o Estado Administrativo deve atuar em relação à proteção do meio ambiente. Ou seja - como pontuam Sarlet, Machado e Fensterseifer -, "todos os entes federativos são 'chamados' pela $\mathrm{CF} / 88$ a atuarem legislativa e administrativamente nas matérias basilares da nossa estrutura político-normativa, entre elas a proteção do ambiente." 28 Os deveres ambientais pautam, por conseguinte, o exercício das competências públicas.

Como leciona Gomes Canotilho, tais normas constitucionais são determinantes de tarefas ou finalidades estatais e impõem ao legislador e às demais autoridades "o dever de adoptar medidas de proteção adequada ao meio ambiente", inclusive em seu caráter dinâmico, "que implica um permanente actualização e aperfeiçoamento dos instrumentos jurídicos destinados à proteção do ambiente perante os novos perigos de agressões ecológicas" ${ }^{\prime 29} \mathrm{O}$ que importa dizer que não há imunidade nem passividade ambiental: todas as pessoas políticas, em todas as esferas, são titulares de competências ambientais - legislativas e administrativas - o que há de se refletir de modo proativo e renovador no exercício das competências atribuídas aos órgãos e entidades da Administração direta e indireta.

Demais disso, o Direito Ambiental se estrutura de modo a conjugar os direitos fundamentais ao meio ambiente ecologicamente equilibrado aos deveres fundamentais de preservação ambiental. O que importa dizer que o Estado Administrativo Ambiental é detentor de competências caleidoscópicas, que instalam relações jurídicas bilaterais, multipolares e difusas, simultaneamente a defender direitos e cobrar deveres das pessoas privadas. Daquele Estado Administrativo que primava pela omissão, num cenário em que as pessoas privadas não detinham direitos subjetivos públicos, tudo mudou: hoje, são direitos e deveres a se integrar na vivência ambientalista.

${ }^{28}$ SARLET, Ingo Wolfgang; MACHADO, Paulo Affonso Leme; FENSTERSEIFER, Tiago. Constituição e Legislação Ambiental Comentadas. São Paulo, SP: Saraiva, 2015, p. 79.

29 GOMES CANOTILHO, José Joaquim. O Direito ao Ambiente como Direito Subjectivo. In: José Joaquim Gomes Canotilho. Estudos sobre Direitos Fundamentais. Coimbra: Coimbra Editora, 2004, p. 182. 


\title{
VII. CONSIDERAÇÕES FINAIS: O ESTADO ADMINISTRATIVO QUE NÃO SE CANSA DE SURPREENDER
}

\begin{abstract}
Se fosse possível a um jurista particularmente interessado pelas coisas do direito público entrar no sono da princesa da fábula, não precisaria deixar correr os cem anos para descobrir atônito que à sua volta tudo mudou. Bastava-lhe ter esperado pelo desencanto dos últimos vinte anos e verificaria que o seu castelo de construções e os seus servidores estariam irremediavelmente submersos no silvado duma nova realidade, perante o qual se encontravam indefesos. E o dramático, quase trágico, é que não há forças benfazejas que rasguem novas clareiras e tracem novas sendas para um regresso ao velho mundo, como numa readmissão ao paraíso e, apesar de tudo, de muitos lados se nota o esforço para mergulhar na realidade com um arsenal obsoleto e, pior ainda, com um pathos dissonante com os tempos. Como um cavaleiro de elmo emplumado que galhardamente lançasse um repto a um carro de assalto. ${ }^{30}$
\end{abstract}

Com estas palavras, carregadas de poesia, Rogério Soares fez a abertura de seu profético Direito e Sociedade Técnica, originalmente publicado ao final da década de 1960.

Mal sabia o Mestre que, quase cinquenta anos depois, o desencanto do jurista dá-se da noite para o dia: o sono da princesa não precisa ser longo. De um dia para o outro, o Estado Administrativo não se cansa de surpreender àqueles que dele esperavam algum comportamento preconcebido. O que apenas aumenta os incentivos para que olhemos com atenção o Estado que nos cerca, abdiquemos de visões preconceituosas e nos dediquemos a desenvolver novas ferramentas para o seu exame. Esse é o chamado que não cessa de nos conclamar ao estudo apurado do Estado Administrativo brasileiro.

30 SOARES, Rogério Ehrhardt. Direito Público e Sociedade Técnica. Coimbra: Editora Tenacitas, 2008. A primeira edição é de 1969. 


\section{REFERÊNCIAS}

ALMEIDA, Fernando Dias Menezes de. Formação da Teoria do Direito Administrativo no Brasil. São Paulo, SP: Quartier Latin, 2015.

BAER, Werner. A Economia Brasileira. $2^{2}$ ed. Trad. Edite Sciulli. São Paulo, SP: Nobel, 2003.

BANDEIRA DE MELLO, Oswaldo Aranha. Princípios Gerais de Direito Administrativo, Vol. I. 2 ${ }^{\underline{a}}$ ed. Rio de Janeiro, RJ: Forense, 1979.

COMPARATO, Fábio Konder. Legitimidade do Poder de Reforma Constitucional. In: Fábio Konder Comparato. Direito Público: Estudos e Pareceres. São Paulo, SP: Saraiva, 1996.

ESTORNINHO, Maria João. Concessão de Serviço Público: que futuro? Direito e Justiça, Vol. Especial (VI Colóquio Luso-Espanhol de Direito Administrativo), 2005.

GOMES CANOTILHO, José Joaquim. Direito Constitucional e Teoria da Constituição. $5^{\mathrm{a}}$ ed. Coimbra: Almedina, 2002.

. Estado Constitucional Ecológico e Democracia Sustentada. In:

Heline Sivini Ferreira; José Rubens Morato Leite (Orgs.). Estado de Direito Ambiental: tendências, aspectos constitucionais e diagnósticos. Rio de Janeiro, RJ: Forense Universitária, 2004.

. Estado de Direito. Lisboa: Gradiva, 1999.

. O Direito ao Ambiente como Direito Subjectivo. In: José Joaquim Gomes Canotilho. Estudos sobre Direitos Fundamentais. Coimbra: Coimbra Editora, 2004. 
. O Direito Constitucional passa; o Direito Administrativo passa também. Studia Juridica, Vol. 61: Estudos em Homenagem ao Prof. Doutor Rogério Soares (Ad Honorem, 1), 2001.

. O Estado Garantidor: claros-escuros de um conceito. In: António Avelãs Nunes e Jacinto Nelson de Miranda Coutinho (Coords.). O Direito e o Futuro, o Futuro do Direito. Coimbra: Almedina, 2008.

GONÇALVES, Pedro Costa. A Concessão de Serviços Públicos: uma aplicação da técnica concessória. Coimbra: Almedina, 1999.

. Direito Administrativo da regulação. In: Pedro Costa Gonçalves. Regulação, Electricidade e Telecomunicações: estudos de Direito Administrativo da Regulação. Coimbra: Coimbra Editora, 2003.

. Entidades Privadas com Poderes Públicos: O Exercício de Poderes Públicos de Autoridade por Entidades Privadas com Funções Administrativas. Coimbra: Almedina, 2005.

GUANDALINI JÚNIOR, Walter. História do Direito Administrativo Brasileiro: Formação (1821-1895). Curitiba, PR: Juruá, 2016.

HÄBERLE, Peter. El Estado Constitucional. Trad. Héctor Fix-Fierro. Ciudad del México: Universidad Nacional Autónoma de México, 2001.

JORDANO FRAGA, Jesús. El Derecho Ambiental del Siglo XXI. Revista de Direito Ambiental, Vol. 9, 36, 2004.

LAGO, Luiz Aranha Corrêa do. A retomada do crescimento e as distorções do "milagre": 1967-1973. In: Marcelo de Paiva Abreu (Org.). A Ordem do Progresso: Cem Anos de Política Econômica Republicana, 1889-1989. Rio de Janeiro, RJ: Campus, 1990. 
MARQUES, Maria Manuel Leitão. O Acesso aos Mercados Regulados e o Direito da Concorrência. Revista de Direito Público da Economia RDPE, Vol. 1, 3, 2003.

MARQUES NETO, Floriano de Azevedo, A Bipolaridade do Direito Administrativo e sua Superação. In: Carlos Ari Sundfeld; Guilherme Jardim Jurksaitis (Orgs.). Contratos Públicos e Direito Administrativo. São Paulo, SP: Malheiros Editores/SBDP/FGV, 2015.

MERKL, Adolf. Teoría General del Derecho Administrativo. Madri: Editorial Revista de Derecho Privado, 1935.

MOREIRA, Egon Bockmann. Anotações sobre a História do Direito Econômico Brasileiro (Parte I: 1930-1956). Revista de Direito Público da Economia - RDPE, Vol. 2, 6, 2004.

. O Princípio da Legalidade, a Lei e o Direito. In: Thiago Marrara (Org.). Princípios de Direito Administrativo: Legalidade, Segurança Jurídica, Impessoalidade, Publicidade, Motivação, Eficiência, Moralidade, Razoabilidade, Interesse Público. São Paulo, SP: Atlas, 2012.

. Processo Administrativo: Princípios Constitucionais, a Lei 9.784/1999 e o Código de Processo Civil/2015. $5^{\text {a }}$ ed. São Paulo, SP: Malheiros Editores, 2017.

. Qual é o Futuro do Direito da Regulação no Brasil? In: Carlos Ari Sundfeld; André Rosilho (Orgs.). Direito da Regulação e Políticas Públicas. São Paulo, SP: Malheiros Editores/SBDP, 2014.

MOREIRA, Egon Bockmann; BAGATIN, Andreia Cristina. Lei Anticorrupção e quatro de seus principais temas: Responsabilidade Objetiva, Desconsideração Societária, Acordos de Leniência e 
Regulamentos Administrativos. Revista de Direito Público da Economia - RDPE, Vol. 12, 47, 2014.

MOREIRA, Vital. Auto-Regulação Profissional e Administração Pública. Coimbra: Almedina, 1997.

NUNES, António José Avelãs. Industrialização e Desenvolvimento: a economia política do "modelo brasileiro de desenvolvimento". São Paulo, SP: Quartier Latin, 2005.

ORLANDO, Vittorio Emanuele. Principii di Diritto Amministrativo. $4^{\underline{a}}$ ed. Firenze: G. Barbèra, 1910.

SARLET, Ingo Wolfgang; MACHADO, Paulo Affonso Leme; FENSTERSEIFER, Tiago. Constituição e Legislação Ambiental Comentadas. São Paulo, SP: Saraiva, 2015.

SCHIMIDT-ASSMANN, Eberhard. La Teoría General del Derecho Administrativo como Sistema: Objetos e Fundamentos de la Constitución Sistemática. Trad. Mariano Bacigalupo, et. al. Madrid: Instituto Nacional de Administración Pública/Marcial Pons, 2003.

SOARES, Rogério Ehrhardt. Direito Público e Sociedade Técnica. Coimbra: Editora Tenacitas, 2008.

TÁCITO, Caio. Direito Administrativo. São Paulo, SP: Saraiva, 1975. WEIL, Prosper. O Direito Administrativo. Trad. Maria da Gloria Ferreira Pinto. Coimbra: Almedina, 1977.

VENÂNCIO FILHO, Alberto. Intervenção do Estado e Liberdade Econômica no Direito Constitucional Brasileiro. In: Paulo Bonavides, et. al. As Tendências Atuais do Direito Público: Estudos em Homenagem ao Professor Afonso Arinos de Melo Franco. Rio de Janeiro, RJ: Forense, 1976. 
VOGEL, Steven. Freer Markets, More Rules: Regulatory Reform in Advanced Industrial Countries. New York, NY: Cornell University Press, 1996.

Notas sobre o Estado Administrativo: de Omissivo a Hiperativo Notes on Administrative State: from Omissive to Hyperactive Submetido em: 2017-06-21 Aceito em: 2017-07-29 